\title{
A Conceptual Framework for Modelling the Thermal Conductivity of Dry Green Roof Substrates
}

\author{
Nataliia Gerzhova, ${ }^{\mathrm{a}, *}$ Jean Côté, ${ }^{\mathrm{a}}$ Pierre Blanchet, ${ }^{\mathrm{a}}$ Christian Dagenais, ${ }^{\mathrm{a}, \mathrm{b}}$ and \\ Sylvain Ménard ${ }^{\mathrm{c}}$
}

\begin{abstract}
The fire performance of green roofs has never been assessed numerically. In order to simulate its fire behavior, the thermal conductivity of a growing media must be determined as an important input parameter. This study characterized the thermal conductivity of a dry substrate and its prediction as a function of temperature, considering temperature effects on soil organic and inorganic constituents. Experimental measurements were made to provide basic information on thermophysical parameters of the substrate and its components. Thermogravimetric analysis was conducted to consider the decomposition of organic matter. An existing model of the thermal conductivity calculation was then applied. The results of calculated and measured solid thermal conductivity showed close values of 0.9 and $1.07 \mathrm{~W} / \mathrm{mK}$, which demonstrates that the model provided a good estimation and may be applied for green roof substrates calculations. The literature data of a temperature effect on soil solids was used to predict thermal conductivity over a range of temperatures. The results showed that thermal conductivity increased and depended on porosity and thermal properties of the soil mineral components. Preliminary validation of obtained temperature-dependent thermal conductivity was performed by experiments and numerical simulation.
\end{abstract}

Keywords: Green roof; Growing medium; Green roof substrate; Thermal conductivity; High temperature

Contact information: a: NSERC Industrial Research Chair on Eco-responsible Wood Construction (CIRCERB), Department of Wood and Forest Sciences, Université Laval, Québec, QC, Canada;

b: FPInnovations, Quebec, QC, Canada; c: Université du Québec à Chicoutimi (UCAQ), Chicoutimi, QC, Canada; *Corresponding author: nataliia.gerzhova.1@ulaval.ca

\section{INTRODUCTION}

The technology of green roofs was developed several decades ago (Dunnett and Kingsbury 2008). Numerous research studies have investigated the advantages of such roofs over conventional roofs. Installing such roofs on buildings has a positive impact on the urban environment and on the building itself, mainly as a tool to reduce energy consumption (Becker and Wang 2011; Jaffal et al. 2012; Saadatian et al. 2013). Promoting green roof installation is essential for the development of this technology, as its effectiveness for the improvement of environmental conditions (urban heat island mitigation, purifying air) can become significant only under the condition of widespread use (Yang et al. 2008; Pompeii and Hawkins 2011). However, the security of this technology in terms of fire safety has not been assessed scientifically yet. There is a common belief that a vegetated roof may protect the house, preventing the spread of fire. Although not supported by scientific evidence, such an opinion is not surprising, considering that plants consist of up to $95 \%$ water. Moreover, organic soils usually contain some amount of water in natural conditions, and they rarely dry out completely. However, 
regulations for such roofs in the province of Quebec, Canada, contain extensive provisions for fire protection (RBQ 2015). Together with the organic part of growing medium, plants compose a fuel load that may contribute to fire propagation. Especially in hot seasons or drought periods, plants, as well as growing medium, may dry out and ignite easily. This poses a risk to a roof deck made of materials that are susceptible to elevated temperatures (e.g., wood, metal). Given the complexity of testing the fire resistance performance of green roof coverings, numerical modelling of heat transfer through the roof assembly can be considered a useful tool. Studies on heat transfer analysis through green roofs were conducted before by many authors (Ouldboukhitine et al. 2011; Tabares-Velasco and Srebric 2012; Chen et al. 2015; Quezada-García et al. 2017). The models, however, were developed for normal temperatures, assessing the performance of such roofs in real conditions. Also, particular attention was paid to the effect of moisture present in soil, and associated mass transfer problem. To study the performance of green roofs in fire by modelling, their response to extreme temperatures should be analyzed considering temperature-induced changes in materials and properties.

Several previous studies predicting temperature distribution in soil under high heat exposure have been conducted and experimentally verified. Campbell et al. (1995) modelled various mineral soils differing in mineralogy, bulk density, water content, and texture, with good predictions of temperatures compared to experimental results. However, they noted that the results depend on the thermal conductivity of soil at elevated temperatures, which was assumed to depend mainly on the changes of the air thermal conductivity in pores. Thermal properties of solid components were assumed to be independent of temperature (Campbell et al. 1994). To determine the temperature distribution in several volcanic soils, Antilén et al. (2006) applied some simplifications for the mathematical model, which fitted the measured temperatures. The simplified models used two separate values for the thermal parameters, below and above $100{ }^{\circ} \mathrm{C}$. They concluded that the thermal characteristics of soil were essential in successful modelling. Suggestions were made for considering thermal decomposition of organic matter (OM), which may influence temperature evolution and thus improve the prediction. Two other studies on predicting temperature profiles during extreme surface heating were conducted on dry sands (Pourhashemi et al. 1999; Enninful 2006). Both studies were in good agreement with the laboratory measurements, provided that temperature-dependent thermal conductivity was used. Linear relationships of thermal conductivity on temperature were established and found appropriate for simulations.

Developing an adequate heat transfer model for the green roof system thus primarily requires the knowledge of temperature-dependent characteristics of its components. The top layer of a green roof assembly is a growing medium, which is usually a mixture (or "mix") of different inorganic (sand, lightweight aggregate) and organic materials (peat, compost). The resulting engineered soil blends differ from natural soils by having a lighter weight and the presence of recycled materials such as fly ash or building waste (Molineux et al. 2009; Carson et al. 2012). Therefore, existing data on thermal conductivity of natural soils and associated property models may not be representative of green roofs. It is thus necessary to properly determine this parameter that constitutes key input data for thermal modelling. Because the risk of fire ignition and propagation is the highest when the plants and growing medium are dry, characterizing the growing medium in this most hazardous case would be considered conservative for simulation purposes.

Thermal properties of green roof growing media have been studied previously by direct measurements at ambient temperatures. Apart from moisture content, which 
generally has a huge impact, the various components and their proportions in a mix also have a noticeable effect on the experimental results (Coma et al. 2016). Increasing the amount of organic material or using lightweight aggregates reduces the overall density of soil, which results in lower thermal conductivity (Sailor et al. 2008; Sandoval et al. 2017). There is also a strong dependence of the thermal conductivity on the type of aggregates used in the mix (Sailor and Hagos 2011). Due to this sensitivity to variations in mixing proportions as well as to components themselves, it is of utmost importance to characterize green roof growing media (green roof substrate) that is typically used in the Province of Quebec (Canada), containing certain components and in certain proportions. Additionally, the effect of heat on the organic and inorganic part has to be taken into consideration. It is generally known that thermal conductivity of most of the minerals and rocks changes inversely with temperature (Eppelbaum et al. 2014). Loss of the organic matter (OM) due to a thermal decomposition leads to changes in proportions in the mix. Lastly, elevated temperatures may induce sufficient thermal gradients in the dry porous space to initiate interparticle radiation which has the potential to greatly increase heat transfer compared to conduction alone (Fillion et al. 2011).

This study predicted the thermal conductivity of a dry green roof growing medium at different temperatures, considering changes induced by heat on its components and structure, for future computer models of green roof assembly in fire. First, thermal conductivity at ambient temperature was determined and validated, adapting an existing thermal conductivity model for dry soils specifically for a green roof substrate. Secondly, having this value as a starting point, the thermal conductivity as a function of temperature was predicted. The prediction was based on the general tendency of thermal conductivity change with temperature for the minerals, the degradation of $\mathrm{OM}$, and the effect of interparticle radiation. Finally, a preliminary validation was performed to illustrate the performance of the thermal conductivity model over the entire range of temperature during fire.

\section{FRAMEWORK FOR MODELING THERMAL CONDUCTIVITY}

\section{Thermal Conductivity of Dry Soils}

Thermal conduction in soils is a complex process that occurs through solids, fluid phases, and through the contacts between solid particles (Robertson 1988). This requires taking several factors into account, such as porosity and shape of grains, which may substantially reduce the effective thermal conductivity. Green roof substrate is highly porous, and heat is transferred much less effectively through its voids, especially in a dry state as air thermal conductivity is only $0.024 \mathrm{~W} / \mathrm{mK}$ (Bergman and Incropera 2011). Under such conditions, heat transmission is expected to occur mostly through the solid phase. However, presence of contacts between particles has a certain resistivity, which also weakens heat conduction. Due to this, thermal conductivity depends mostly on the contact parameters (Robertson 1988).

The estimation of the thermal conductivity of a dry soil can be made using existing models for granular materials. This paper uses the model from Côté and Konrad (2009), as it integrates the effect of structure on the effective thermal conductivity in two-phase geomaterials. The semi-theoretical model allows determination of the effective thermal conductivity from the volume fractions (based on porosity $n$ ) and the thermal conductivities of solid and fluid phases, 


$$
\lambda=\frac{\left(\kappa_{2 P} \lambda_{s}-\lambda_{f}\right)(1-n)+\lambda_{f}}{1+\left(\kappa_{2 P}-1\right)(1-n)}
$$

where $\lambda_{s}$ and $\lambda_{f}(\mathrm{~W} / \mathrm{mK})$ are the thermal conductivities of solid and fluid phases respectively. In present study $\lambda_{f}$ is the thermal conductivity of air, as a fluid component of a dry soil. The variable $\kappa_{2 \mathrm{P}}$ is a dimensionless empirical structure parameter that characterizes the density of contact between particles, which mainly depends on their shape and the presence of cementation. In the study, three types of materials were identified by the shape of their particles, namely rounded (providing a small contact area), cemented (with a good contact), and angular (somewhere between rounded and cemented). For each type of material, the dependency of $\kappa_{2 p}$ on the ratio $\lambda_{f} / \lambda_{s}$ was experimentally determined. Figure 1 shows that the smaller the thermal conductivity ratio, the lower the values of $\kappa_{2 \mathrm{p}}$. Low values of $\kappa_{2 p}$ in Eq. 1 lead to lower values of thermal conductivity. Figure 1 shows that rounded particles have lower values of $\kappa_{2}$ and thus greater particle to particle contact resistance compared to angular and cemented particles. Also, decreasing thermal conductivity ratios leads to increased dependency on the particle shape. Structure effect reduces to none at values of $\kappa_{2}$ p higher than $1: 15$.



Fig. 1. Dependence of structure parameter $\kappa_{2} \mathrm{P}$ on the $\lambda_{f} / \lambda_{s}$ ratio and on the structure (redrawn from Côté and Konrad 2009)

$\beta$ represents an empirical parameter for the slopes for each type of material, with which $\kappa_{2 \mathrm{p}}$ is determined in Eq. 2.

$$
\kappa_{2 P}=0.29\left(15 \frac{\lambda_{f}}{\lambda_{s}}\right)^{\beta}
$$

All the values of $\kappa_{2 \mathrm{P}}$ lay within Hashin-Shtrikman bounds (HSU and HSL) (Hashin and Shtrikman 1962) applied to thermal conductivity, which represent the upper and the lower bounds of an effective thermal conductivity of a composite material. They are derived based on the shape, volume, and arrangement of particles of one phase with respect to the other. In Fig. 1, the upper bound characterizes a material with a continuous solid phase, while the lower bound is for a continuous fluid phase (Côté and Konrad 2009). 
As the presented model was developed for the rock materials without OM, this research laboratory work needs to be carried out first to obtain several thermo-physical parameters of the growing medium. Some results of soil conductivity measurements will also serve to verify the accuracy of the model.

\section{Thermal Conductivity of the Solid Phase}

For the model, thermal conductivity of a solid phase is required. For materials consisting of several components, the geometric mean method gives relatively accurate results using thermal conductivities of each mineral components $\left(\lambda_{i}\right)$ and their volume fractions $\left(x_{i}\right)$.

$$
\lambda_{s}=\prod \lambda_{i}^{x_{i}}
$$

This method is also suitable for soil saturated with water,

$$
\lambda=\lambda_{s}^{1-n} \cdot \lambda_{w}^{n}
$$

where $\lambda$ is a total thermal conductivity of a soil $(\mathrm{W} / \mathrm{mK}), \lambda_{s}$ is the thermal conductivity of solid material $(\mathrm{W} / \mathrm{mK}), \lambda_{w}$ is the thermal conductivity of water $(\mathrm{W} / \mathrm{mK})$, and $n$ is the porosity (from 0 to 1 ). Equation 4 is particularly interesting when the thermal conductivity of the solid phase needs to be assessed when no solid parent rock cores are available for direct measurements. Instead, the thermal conductivity of the solids can be easily backcalculated from the global thermal conductivity $(\lambda)$ of a mix of solid and water (fully saturated) and by knowing the thermal conductivity of water and by solving Eq. 4 for $\lambda_{s}$. This technique will indeed be illustrated later in the paper.

\section{Effect of Temperature}

Solid particles

Due to several processes taking place simultaneously during burning and the need for fire and temperature proof measuring devices, direct measurements of thermal properties at high temperatures are extremely difficult to conduct. Therefore, this study will rely on existing data from the literature to predict the changes in these properties with temperatures.

Literature contains large amounts of data on thermal properties of rocks and minerals as functions of temperature (Clark 1966; Čermák and Rybach 1982; Robertson 1988). However, as green roof soil is a mixture of different components of different origins, it is difficult to associate it to a particular rock. In this case it would be better to use generalized values.

Variations in thermal conductivity studied by Vosteen and Schellschmidt (2003) were given at temperatures between 0 and $300{ }^{\circ} \mathrm{C}$ and showed similar decreasing behavior with temperature for magmatic, metamorphic, and sedimentary groups. Based on the results, they formulated a general equation for temperature dependence for all groups of rocks. Research of Clauser and Huenges (1995) has analyzed existing data for rocks at different temperatures from several researches on rocks and minerals. They developed curves for four basic groups of rocks for a temperature range from 0 to 800 to $1200{ }^{\circ} \mathrm{C}$. Another study is of Zoth and Haenel (1988), who also collected and examined existing data on rocks, and sorted the results in six groups (salt rocks, limestone, metamorphic rocks, acid rocks, basic and ultrabasic rocks). For each group, a simple formula was given as a mean curve of the results, 


$$
\lambda(T)=\frac{A}{350+T}+B
$$

where constants $\mathrm{A}$ and $\mathrm{B}$ were provided for each group and $\mathrm{T}$ is the temperature $\left({ }^{\circ} \mathrm{C}\right)$. However, if normalizing all groups of rocks with Eq. 6, the same slope is obtained and is shown in Fig. 2,

$$
\lambda_{n}=\frac{\lambda_{T}-\lambda_{T 2}}{\lambda_{T 1}-\lambda_{T 2}}
$$

where $\lambda_{n}$ is the normalized value (from 0 to 1 ), $\lambda_{T}$ is the value at a certain temperature $(\mathrm{W} / \mathrm{mK})$, and $\lambda_{T 1}$ and $\lambda_{T 2}$ are values at $0{ }^{\circ} \mathrm{C}$ and $800{ }^{\circ} \mathrm{C}(\mathrm{W} / \mathrm{mK})$.

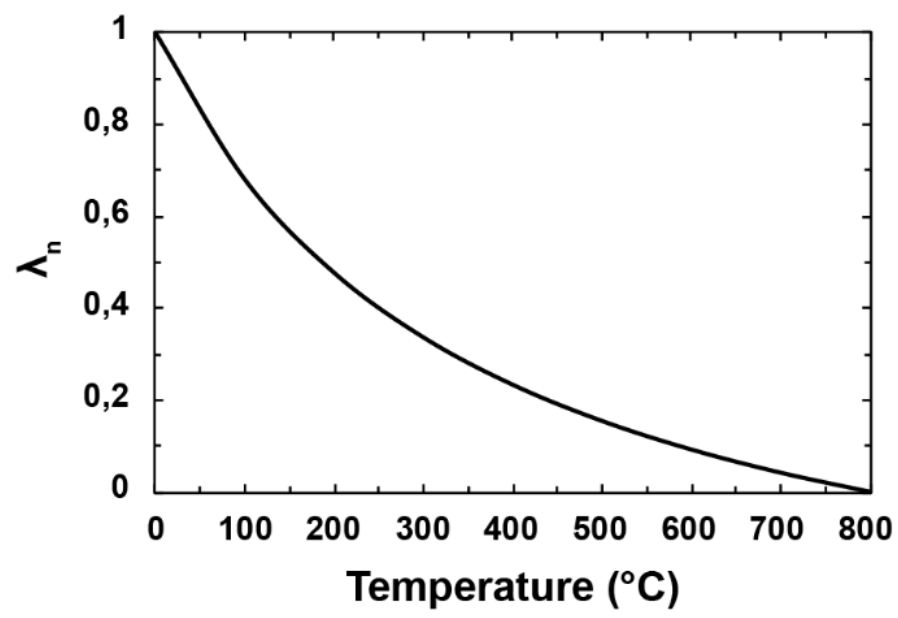

Fig. 2. Normalized thermal conductivity $\left(\lambda_{n}\right)$ as a function of temperature

This normalized relation can be applied for predicting the thermal conductivity of growing medium solids at a given temperature range. However, it requires knowledge of its starting and ending points. Solid thermal conductivity at a reference temperature as a starting point can be modeled with Eq. 3. For $\lambda_{s}$ at $800{ }^{\circ} \mathrm{C}$, the ratio of thermal conductivities at $0{ }^{\circ} \mathrm{C}$ and $800{ }^{\circ} \mathrm{C}$ from Zoth and Haenel (1988) may be taken. In their study, the mean curve for all groups of rocks, except rock salts and ultrabasic rocks, was obtained with A and B constants equal to 770 and 0.7, respectively. From that, $\lambda_{T 1}$ and $\lambda_{T 2}$ are 2.9 and $1.37 \mathrm{~W} / \mathrm{mK}$, respectively, which gives the ratio of 2.2.

\section{Fluid component}

As air is a fluid component of soil, changes in its thermal conductivity $\left(\lambda_{f}\right)$ with temperature must be considered. It increases from 0.024 at room temperature to 0.71 at $800^{\circ} \mathrm{C}$, which is shown in Fig. 3 (Bergman and Incropera 2011).

\section{Effect of Radiation}

Another factor that can influence heat conduction in the growing medium may be taken into consideration. Elevated temperature can induce interparticle radiation heat transfer, which flows in the same direction as conduction heat transfer. Howell and Siegel (2010) proposed to mathematically express this process through the diffusion approximation of the Fourier conduction law. 


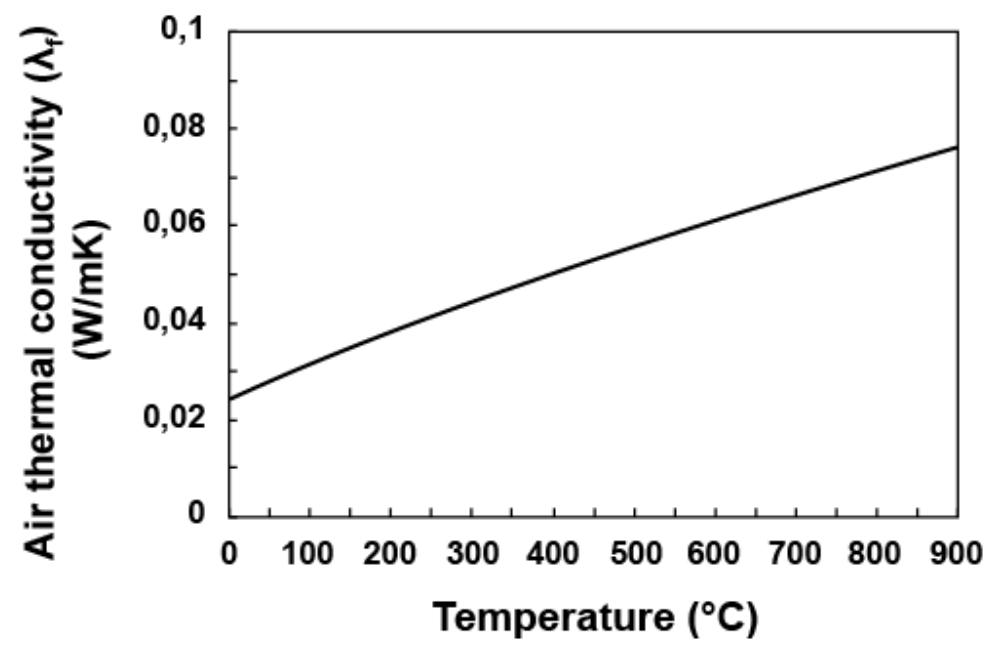

Fig. 3. Temperature dependence of air thermal conductivity $\left(\lambda_{f}\right)$

The effective thermal conductivity $\lambda_{e}$ was defined as the sum of the contributions from interparticle radiation $\lambda_{\text {rad }}$ and that from pure conduction $\lambda_{c}$ (Tien and Drolen 1987; Kaviany 1995),

$$
\lambda_{e}=\lambda_{c}+\lambda_{\text {rad }}
$$

where $\lambda_{\text {rad }}$ is given by,

$$
\lambda_{\text {rad }}=4 E d_{10} \sigma T^{3}
$$

where $E$ is the exchange factor, $d_{10}$ is the particle diameter $(\mathrm{m}), \sigma$ is Stefan-Boltzman constant equal to $5.67 \times 10^{-8}\left(\mathrm{~W} / \mathrm{m}^{2} \mathrm{~K}^{4}\right)$, and $T$ is the temperature $(\mathrm{K})$. The exchange factor depends on the particle emissivity $\varepsilon_{p}$ (Fillion et al. 2011). Using the equation of Argo and Smith (1953) yielded good prediction (Fillion et al. 2011):

$$
E=\frac{\varepsilon_{p}}{2-\varepsilon_{p}}
$$

\section{EXPERIMENTAL}

To obtain the parameters required to model the thermal conductivity of green roof substrate, several experimental measurements were made. Thermal decomposition analysis was needed to be able to account for the degradation of the organic part of the soil during calculation of the total soil conductivity at elevated temperatures. Also, for the determination of porosities of materials, the densities of solid particles of each component and a soil mix were measured, which then were used to evaluate thermal conductivities of solids. Porosity was determined as,

$$
n=1-\frac{\rho_{\text {total }}}{\rho_{s}}
$$

where $\rho_{\text {total }}$ is the bulk density $\left(\mathrm{g} / \mathrm{cm}^{3}\right)$ and $\rho_{s}$ is the density of solid particles $\left(\mathrm{g} / \mathrm{cm}^{3}\right)$.

Finally, measurements of thermal conductivities of growing medium and each of its components were performed. 


\section{Materials Preparation}

For the laboratory work, a commercially available green roof substrate, commonly used in the Province of Québec, was studied. A typical mix consists of sand, lightweight aggregate (with porous granules), and organic product (in the form of composting material). The total amount of $\mathrm{OM}$ is around $20 \pm 4 \%$ by mass. The mix was tested as is and for some experiments, each component of this mix was tested separately in dry and saturated states. Before experiments in a dry state, soil was placed in an oven at $105{ }^{\circ} \mathrm{C}$ for $24 \mathrm{~h}$ or until it reached a constant mass. Afterwards, the soil was placed in plastic bags, sealed, and stored until it was analyzed.

\section{Thermal Decomposition Analysis}

To characterize the decomposition behavior of the organic components of the soil, an experimental thermal decomposition analysis was conducted. This test serves to determine the variation of mass with temperature (Todor 1976). The sample was heated in a furnace at a constant rate under controlled conditions and its mass was continuously recorded yielding a continuous mass-temperature relationship.

Before the analysis, soil was first dried in the oven, and then it was ground into powder in a laboratory sample grinder. The weight of samples was between 17 and 22 $\mathrm{mg}$. The tests were performed by thermogravimetric analyzer Mettler Toledo TGA/DTA 851e (Schwerzenbach, Switzerland). During each test, furnace temperature was raised from 25 to $900{ }^{\circ} \mathrm{C}$ with a heating rate of $10{ }^{\circ} \mathrm{C} / \mathrm{min}$ under air. The experiment was conducted three times with the same conditions.

\section{Density of Solid Particles}

Prior to thermal conductivity measurements, it was necessary to know densities of the particles of each material. Small amounts of all samples were saturated with water. Knowing volumes and masses of the sample and water, as well as the density of water, the volume of material can be calculated, from which it is possible to find out the density of solid material ASTM D854-14 (2014).

\section{Thermal Conductivity}

\section{Sample preparation}

The following materials were taken for the experimental part: soil mix and each of its separate components (sand, lightweight aggregate, and compost). Additionally, some modifications were made to these materials, except the sand. First was the removal of the OM from soil mix and compost in a furnace. Soil mix samples in stainless-steel molds were placed into a muffle furnace. Afterwards, the temperature inside the furnace was gradually brought from 25 to $700{ }^{\circ} \mathrm{C}$ at a rate of $3{ }^{\circ} \mathrm{C} / \mathrm{min}$, and then kept stable for $2 \mathrm{~h}$. Then the samples were taken out from the furnace, cooled, and sealed. The same procedure was done with the compost following standard test method ASTM D2974 (2014) Method C. A second modification is for the lightweight aggregate. Its granules contain voids. In order to remove them and obtain solid particles, aggregate was pulverized into a powder in a grinder.

\section{Equipment}

Two different testing methods of measuring thermal conductivity at a given temperature were used for different materials. The choice of method to be used depends on 
the parameter to be measured and on the type of material as well as sample preparation (effect of structure, saturated $v s$ dry conditions, etc.). Although the focus of this study was on dry growing medium, testing in a saturated state allowed indirect assessment of the thermal conductivity of solids using Eq. 4. A list of all materials, conditions, measurement techniques, and characteristics to determine is presented in Table 1.

For the steady state method, the equipment is designed to create one-dimensional heat flux through the specimen by placing it between plates at constant different temperatures. After reaching a steady state for a specimen, the thermal conductivity is then obtained from Fourier's law. Experiments were conducted in a heat transfer cell equipped with heat flux meters that was first described by Côté and Konrad (2005). A cylindrical specimen of approximately $100 \mathrm{~mm}$ in diameter and between 50 and $75 \mathrm{~mm}$ in height is placed between two heat exchangers. The heat exchangers are connected to an independent temperature-controlled bath. Heat fluxes were measured at both flat ends of the specimen using thermoelectric heat flux meters from Captec, Lille, France. The heat flux meters were equipped with five independent thermocouples for simultaneous temperature measurements on the top and the bottom of the specimen. The heat transfer cell was placed in an insulated box which was kept at a mean temperature of the tested sample. The whole equipment was placed in a cold room, where, for the tests, a temperature of around $4.5^{\circ} \mathrm{C}$ was kept (Fig. 4). For each analysis, temperatures of the top and bottom plates were set at $12{ }^{\circ} \mathrm{C}$ and $2{ }^{\circ} \mathrm{C}$, respectively. The duration of each conductivity test was $24 \mathrm{~h}$.

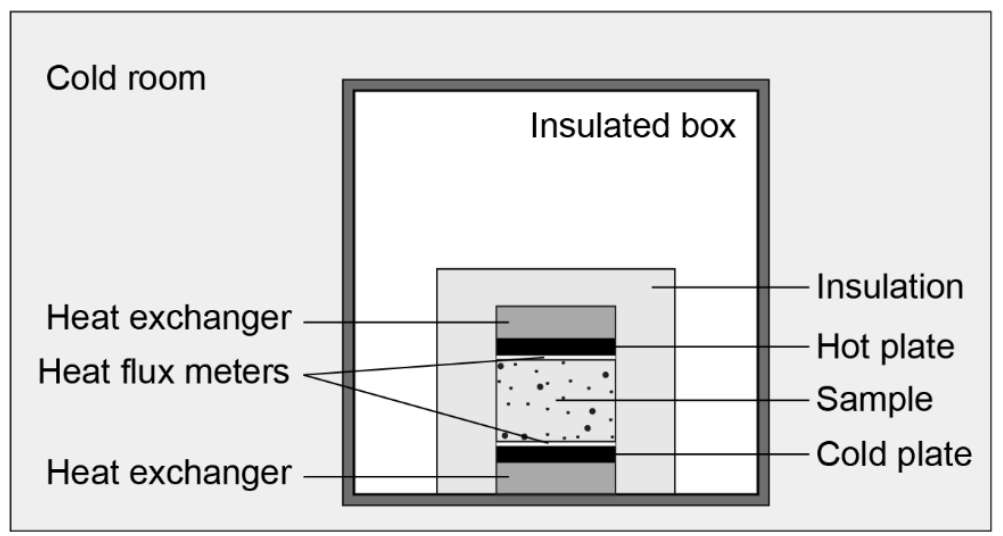

Fig. 4. Steady state measurement

Soil mix was tested in saturated and dry states. Samples for a dry state were compacted manually at four different densities. To ensure that proportions of components were kept the same and for easier compaction, soil was moistened first. After filling a mold and compacting it, the mold was then placed in an oven at $105{ }^{\circ} \mathrm{C}$ to remove all the moisture. Depending on the density, the time in the oven took from 2 to 5 days. Then, while keeping the sample in the mold, it was installed and insulated in the heat transfer cell to measure its thermal conductivity. All the procedures were also performed for a soil mix without OM.

Tests on lightweight aggregate were carried out in a saturated state. Due to the large size of some of its particles, a soft and compressible sheet made of highly conductive silicone with a thickness of $3 \mathrm{~mm}$ was used to create a smooth surface for a better contact between the sample and the upper plate. Such practice was also successfully used by Clarke et al. (2016) to reduce interface resistance between the sample and the plates during the 
measurement of the thermal conductivity of green roof substrates. Compost without OM was tested in a saturated state only.

Measurements of sand, ground aggregate, and compost in a saturated state were conducted by a single needle probe method using the Hukseflux TP02 probe (Delft, Netherlands). It is a standard technique (ASTM D5334-14 (2014)) where the needle is inserted in a soil and acts as a heat source, being heated for a certain period of time. The heat dissipates into the surrounding medium, and a thermocouple inside the needle registers its temperature response and the time. Plotting the temperature against logarithm of time, thermal conductivity is calculated. In this test a polyvinyl chloride (PVC) mold in the form of a long cylinder with a height of $185.7 \mathrm{~mm}$ and an inside diameter of $75 \mathrm{~mm}$ was used (Fig. 5). Saturated material was poured into the mold and then a needle was vertically inserted. The samples were then left for $24 \mathrm{~h}$ for measurements. Each material was tested twice to obtain mean values. After the experiments, samples were placed in an oven at 105 ${ }^{\circ} \mathrm{C}$ for $24 \mathrm{~h}$ or until they reached a constant mass. Samples were then weighed in order to determine the amount of water and solid material.

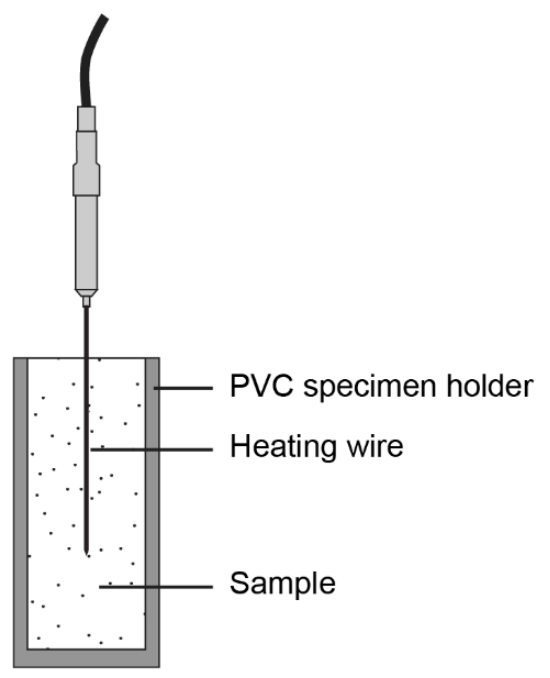

Fig. 5. Needle probe method

Table 1. Summary of Samples and Test Conditions

\begin{tabular}{|c|c|c|c|}
\hline Material & Condition & $\begin{array}{l}\text { Test Method } \\
\text { (Conductivity) }\end{array}$ & Properties to Determine \\
\hline \multicolumn{4}{|l|}{ Total } \\
\hline \multirow[t]{2}{*}{ Soil mix } & saturated & steady & $\lambda_{\mathrm{s}}$ \\
\hline & dry & & $\lambda_{c,} \kappa_{2 \mathrm{P}}$ \\
\hline \multirow[t]{2}{*}{ Soil mix without OM } & saturated & steady & $\lambda_{\mathrm{s}}$ \\
\hline & dry & & $\lambda_{c,} \kappa_{2 \mathrm{P}}$ \\
\hline \multicolumn{4}{|l|}{ Components } \\
\hline Sand & saturated & transient & $\lambda_{\mathrm{s}}$ \\
\hline Aggregate & saturated & steady & $\lambda_{\mathrm{s}}$ \\
\hline Aggregate (ground) & saturated & transient & $\lambda_{\mathrm{s}}$ \\
\hline Compost & saturated & transient & $\lambda_{\mathrm{s}}$ \\
\hline Compost without OM & saturated & steady & $\lambda_{\mathrm{s}}$ \\
\hline
\end{tabular}




\section{RESULTS AND DISCUSSION}

\section{Thermal Decomposition Analysis}

The results of the thermal decomposition analysis are shown in Fig. 6. The mean curve presents the decomposition of a soil mix at several stages. At the beginning of the test, between 40 and $150{ }^{\circ} \mathrm{C}$, there is a small mass loss of 1 to $1.5 \%$, which is related to a dehydration process in the samples. It is probable that not all water was removed by drying the soil in the oven. Also, the material could have absorbed some amount of moisture from the air in the period between drying and thermal analysis when storing or grinding samples. At the second stage, a considerable mass loss of 12.5 to $13.5 \%$ was observed between 250 and 440 to $500{ }^{\circ} \mathrm{C}$ due to a combustion process. Lastly, above $500{ }^{\circ} \mathrm{C}$ the remaining 1 to $1.5 \%$ of OM was removed. After about $700{ }^{\circ} \mathrm{C}$ no change in mass was observed in the samples. The remaining amount of the material shows that only $16.4 \%$ of OM was present in the soil mix.

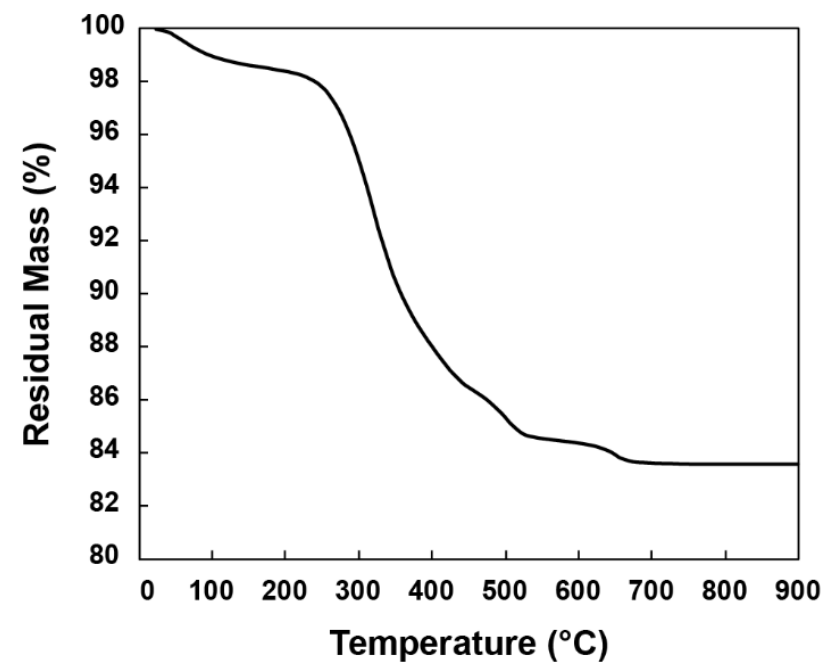

Fig. 6. TG curve of the soil mix decomposition

\section{Density of Solid Particles}

Results for the determination of solid densities are presented in Table 2. The soil with $\mathrm{OM}$ had a smaller density than that without $\mathrm{OM}, 2.22$ compared to $2.47 \mathrm{~g} / \mathrm{cm}^{3}$. The same is true for the compost with the density of its solid particles of $1.76 \mathrm{~g} / \mathrm{cm}^{3}$ and 2.39 $\mathrm{g} / \mathrm{cm}^{3}$ after removing of OM from it.

Table 2. Densities of Solid Particles

\begin{tabular}{|c|c|}
\hline Material & $\begin{array}{c}\rho_{s} \\
\left(\mathrm{~g} / \mathrm{cm}^{3}\right)\end{array}$ \\
\hline Soil mix & 2.22 \\
\hline Soil mix without OM & 2.47 \\
\hline Sand & 2.69 \\
\hline Aggregate particle & 2.10 \\
\hline Aggregate solids (ground) & 2.91 \\
\hline Compost & 1.76 \\
\hline Compost without OM & 2.39 \\
\hline
\end{tabular}




\section{Thermal Conductivity}

Results for porous soil mix (with and without $\mathrm{OM}$ ) and for the solid materials are given. Values obtained from measurements by steady state and by transient method are presented.

\section{Effect of porosity}

Test results of soil mixes with and without OM in a dry state and at different porosities $(n)$ are presented in Table 3. Thermal conductivities for both materials show an increase with a decreasing porosity, with the values from 0.128 to $0.21 \mathrm{~W} / \mathrm{mK}$ for the soil mix and from 0.25 to $0.33 \mathrm{~W} / \mathrm{mK}$ for the mix with no OM. It has to be noted that the mix without OM is more compactible. The minimum porosity obtained by manual compaction was 0.42 , while for the original mix it was only 0.49 . On the opposite side, the presence of $\mathrm{OM}$ allowed a much higher porosity $(0.69)$ due to the bulky nature of the composting material.

Table 3. Results of the Thermal Conductivity Measurements $\left(\lambda_{c}\right)$ in a Dry State and Porosities of Samples

\begin{tabular}{|c|c|c|}
\hline Material samples & $n$ & $\begin{array}{c}\lambda_{c} \text { of the sample } \\
(\mathrm{W} / \mathrm{mK})\end{array}$ \\
\hline Soil mix & 0.49 & 0.210 \\
\hline 1 & 0.59 & 0.180 \\
\hline 2 & 0.61 & 0.135 \\
\hline 3 & 0.69 & 0.128 \\
\hline 4 & & \\
\hline Soil mix without OM & 0.42 & 0.330 \\
\hline 1 & 0.46 & 0.300 \\
\hline 2 & 0.49 & 0.312 \\
\hline 3 & 0.52 & 0.250 \\
\hline 4 &
\end{tabular}

\section{Solid particles}

The results of thermal conductivities of each material obtained in the experiments in a saturated state are presented in Table 4 . Thermal conductivities $\left(\lambda_{c}\right)$ are given together with the porosities $(n)$ that were obtained using Eq. 10 knowing $\rho_{\mathrm{s}}$ from Table 2 and dry density of the sample $\left(\rho_{\text {total }}\right)$. From this data solid thermal conductivity $\lambda_{s}$ was calculated with Eq. 4, using thermal conductivity of water equal to $0.58 \mathrm{~W} / \mathrm{mK}$ at $7{ }^{\circ} \mathrm{C}$, which is mean temperature at which samples were tested.

The measured value of $\lambda_{c}$ of $0.73 \mathrm{~W} / \mathrm{mK}$ for the soil mix (Table 4 ) is close to the range of values found in the literature (between 0.5 and $0.7 \mathrm{~W} / \mathrm{mK}$ ) for the saturation level equal to 1 (Sailor and Hagos 2011). Low values of $\lambda_{s}$ for soil mix with and without OM can be explained by a presence of porous aggregate particles with low thermal conductivity. 
Table 4. Test Results in a Saturated State

\begin{tabular}{|l|c|c|c|c|}
\hline \multicolumn{1}{|c|}{ Material } & $\begin{array}{c}\rho_{\text {total }} \\
\left(\mathrm{g} / \mathrm{cm}^{3}\right)\end{array}$ & $n$ & $\begin{array}{c}\lambda_{c} \\
(\mathrm{~W} / \mathrm{mK})\end{array}$ & $\begin{array}{c}\lambda_{s} \text { (from Eq. 4) } \\
(\mathrm{W} / \mathrm{mK})\end{array}$ \\
\hline \multicolumn{5}{|c|}{ Total } \\
\hline Soil mix without OM & 0.83 & 0.63 & 0.73 & 1.07 \\
\hline Soil mix with & 1.36 & 0.45 & 1.05 & 1.70 \\
\hline Components & 0.36 & 2.03 & 4.12 \\
\hline Sand & 1.72 & 0.53 & 0.68 & 0.82 \\
\hline Aggregate particle & 0.98 & 0.40 & 0.92 & 1.26 \\
\hline Aggregate solids (ground) & 1.74 & 0.85 & 0.66 & 1.35 \\
\hline Compost & 0.26 & 0.70 & 0.81 & 1.80 \\
\hline Compost without OM & 0.71 &
\end{tabular}

\section{Modelling Thermal Conductivity}

Thermal conductivity of solid phase

The thermal conductivity of solids of the total soil mix may be calculated from its constituents using the geometric mean method (Eq. 3). Because the loss of OM occurs with increasing temperature, it is better to consider it as a separate constituent with its own properties. Using the same equation (3), $\lambda_{s}$ of OM can be evaluated from the results of $\lambda_{s}$ for soils with and without OM (Table 4). For that, mass fractions of soil's organic and inorganic parts, obtained from the thermal decomposition analysis and divided by the densities of each of the parts, were transformed into the volume fractions $(x)$ resulting in 0.27 and 0.73 respectively. The density of $\mathrm{OM}\left(1.3 \mathrm{~g} / \mathrm{cm}^{3}\right)$ was taken from the literature (De Vries 1954). As a result, the indirectly assessed thermal conductivity of OM was 0.31 $\mathrm{W} / \mathrm{mK}$. This value is close to values from the literature: De Vries (1954) reported a value of $0.25 \mathrm{~W} / \mathrm{mK}$ for humus, while Campbell et al. (1994) obtained a value of $0.29 \mathrm{~W} / \mathrm{mK}$ for solid peat moss.

Obtaining the thermal conductivity of $\mathrm{OM}$ is also possible from the compost. However, due to high porosity of samples in the experiments (Table 4) the proportion of OM may vary a lot. This remarkably reduces precision in the calculation and thus is not suitable.

Typical growing medium for extensive green roofs contains a large proportion of lightweight aggregate, reaching up to $100 \%$. Pumice, expanded clay, shale, and slate are common materials used. Modeling the thermal conductivity of dry substrates with such materials is complicated by the porous structure of their particles. In the present study, the application of the model (Eq. 1) for prediction of $\lambda_{s}$ of a porous particle is verified. The maximum value of 0.67 for $\kappa_{2 \mathrm{p}}$ must be taken, as it corresponds to a spongy-like structure. Knowing the porosity of a particle from Eq. 10 and previously measured $\lambda_{s}$ of aggregate solids (ground), thermal conductivity of its particle is modeled, resulting in $0.81 \mathrm{~W} / \mathrm{mK}$. It has about a $1 \%$ difference from the measured value equal to $0.82 \mathrm{~W} / \mathrm{mK}$ (Table 4), which shows the suitability of the model for lightweight aggregate characterization. This verification also gives confidence in measured values and allows to safely use the test results in modeling of thermal conductivity of a growing medium.

Thermal conductivity of solids of soil mix and for soil mix without OM may be calculated from their constituents using Eq. 3, which may then be verified with test results. Mass fractions of each component were first converted to volumetric proportions $(x)$ knowing the densities of their solids from Table 2. From the data available from the 
manufacturer on the soil mix recipe, mass proportions of sand, lightweight aggregate, and the inorganic part of compost are $12,42.6$, and $29 \%$ respectively, while OM content is $16.4 \%$, as shown in thermogravimetric analysis. Table 5 presents the obtained volume fractions of components. Considering the decomposition of $\mathrm{OM}$ and thus changing proportions of each component, results for the substrate without OM are presented as well.

Table 5. Volume Fractions $(x)$ of Components

\begin{tabular}{|l|c|c|}
\hline \multirow{2}{*}{ Component } & \multicolumn{2}{|c|}{ Volume Fraction $(x)$} \\
\cline { 2 - 3 } & Soil Mix with 16.4\% of OM & Soil Mix without OM \\
\hline Sand & 0.09 & 0.12 \\
\hline Aggregate & 0.41 & 0.55 \\
\hline OM & 0.25 & - \\
\hline Compost without OM & 0.25 & 0.33 \\
\hline
\end{tabular}

With these values, the calculated $\lambda_{s}$ of the soil mix is equal to 0.9 , which is $15.9 \%$ lower than the measured value of $1.07 \mathrm{~W} / \mathrm{mK}$ (Table 4). For the soil without OM, $\lambda_{s}$ is equal to 1.29 , which is $24 \%$ lower than the experimental result of $1.7 \mathrm{~W} / \mathrm{mK}$ (Table 4 ). The difference may be explained by the uncertainty in the right value of moisture content of organic product during soil blending that leads to some changes in proportions. The presence of highly conductive sand, in comparison to other components, can make the results very sensitive. Considering these aspects, the comparative results presented herein are satisfying.

\section{Thermal conductivity of porous dry green roof soil at a reference temperature}

In this study, the reference temperature is set equal to $7{ }^{\circ} \mathrm{C}$, the average of tested samples. Figure 7 presents measured thermal conductivity values of soil mix and soil without OM at four different porosities each (Table 3). The fitted curves, also shown in the figure, were obtained using Eq. 1, which gave structure parameters $\kappa_{2 \mathrm{p}}$ equal to 0.218 for the soil mix and 0.173 for the soil mix without OM. At $n=0$ and $n=1$, values calculated for the solids (top part of table 4) and the air were taken correspondingly. The figure illustrates the changes in thermal conductivity with increasing porosity for studied materials.



Fig. 7. Change in thermal conductivity $\left(\lambda_{c}\right)$ with porosity from experiments and fitting curves for the soil mix and soil without OM 
$\kappa_{2 \mathrm{P}}$ values calculated for both materials are shown as functions of the $\lambda_{f} / \lambda_{s}$ ratio in Fig. 8. It can be seen that the values lay slightly higher than the slope presenting cemented types of rocks. Although sand and aggregate are more of a rounded shape, the closeness to cemented type may be explained by the specificity of the organic product, which may act as a thermal bridge between particles. It is speculated that in a moist sample that was compacted and then dried, OM created a good contact between particles comparable to cemented rock materials. According to these results, separate values of $\beta$ may be established to characterize the tested growing medium. As $\kappa_{2 \mathrm{p}}$ for both soils with and without OM are close to each other, a common $\beta$ value of 0.30 can be preliminarily used as obtained with Eq. 2 . The thick full line shown in Fig. 8 represents the slope for new $\beta$.

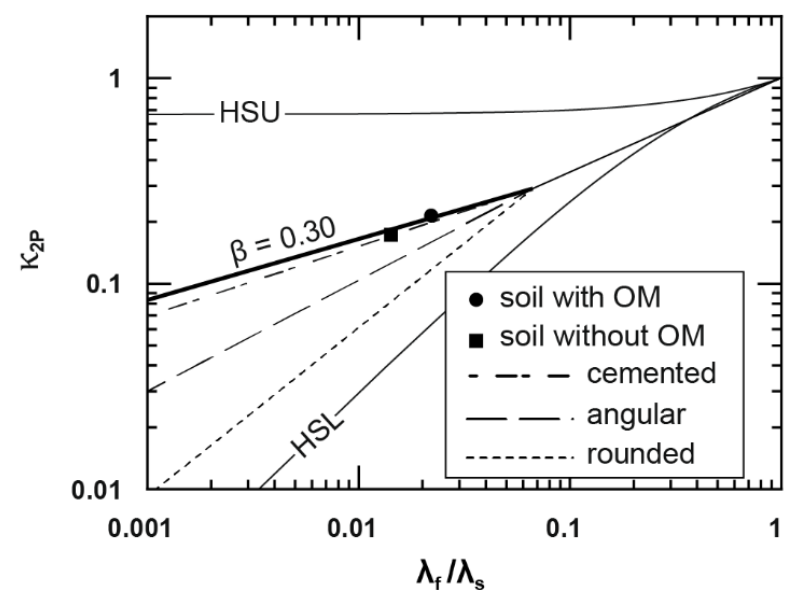

Fig. 8. $\kappa_{2 \mathrm{P}}$ values for soil mixes

\section{Thermal conductivity as a function of temperature}

The laboratory was equipped to analyze the decomposition curve as a function of temperature. Unfortunately, thermal properties (conductivity and radiation) could not be assessed at elevated temperature, so existing models had to be used to describe the effect of temperature $(T)$.

\section{Normalized thermal decomposition analysis curve}

The OM content of typical green roof substrates usually ranges between $3 \%$ and $20 \%$. The content reduces to 0 at temperatures close to $600{ }^{\circ} \mathrm{C}$, as shown in Fig. 6. To be able to account for this variation using a model for any type of substrate, the OM content to $T$ relationship can be modeled using a normalized form. It may be seen from the thermal decomposition analysis that the decomposition curve resembles the curve for soil water characteristic, which can be described using a modified version of the equation developed by Van Genuchten (1980), where the normalized amount of OM $\left(m_{O M n}\right)$ can be modelled as follows,

$$
m_{O M n}=\frac{1}{\left[1+\left(\frac{T}{\alpha}\right)^{n}\right]^{m}}
$$

where $\mathrm{T}$ is in ${ }^{\circ} \mathrm{C} ; \alpha, n$, and $m$ are curve fitting parameters obtained by fitting with the least squares method, equal to $362.26,5.09$, and 1.28 , respectively, from the normalized data of Fig. 6. The resulting new curve for the thermal decomposition of normalized OM content is displayed in Fig. 9. 


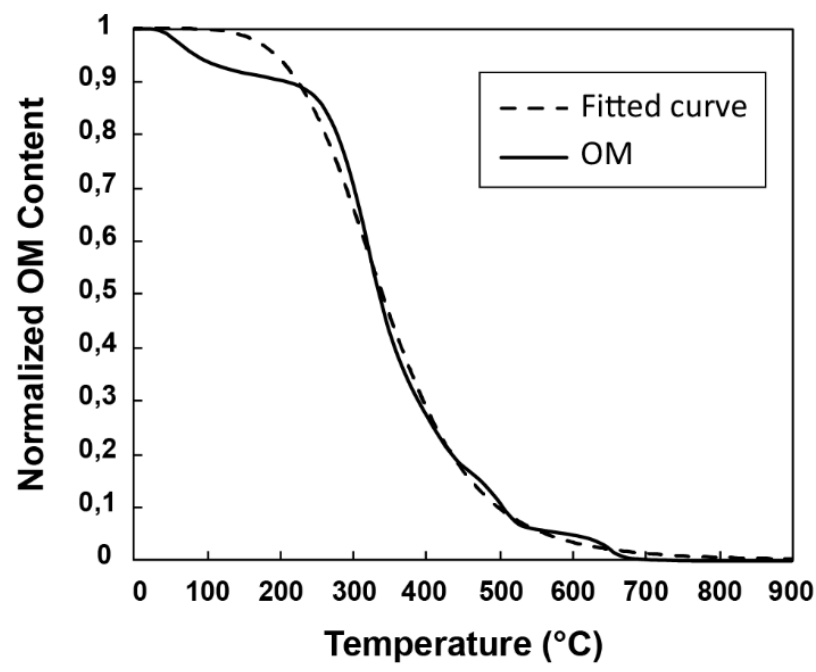

Fig. 9. Thermogravimetric analysis curve of $\mathrm{OM}$ and best-fit curve

\section{Temperature dependence of thermal conductivity of substrate's solids}

Equation 3 is used for the prediction of $\lambda_{s}$ of soil mix at different temperatures considering separately inorganic and organic parts, as well as variations in their volume fractions with temperature. $\lambda_{s}$ of inorganic part of soil mix as a function of temperature is obtained using the normalized curve of Zoth and Haenel (1988), where at $7{ }^{\circ} \mathrm{C}$ it is equal to $1.29 \mathrm{~W} / \mathrm{mK}$, which is the previously calculated thermal conductivity of soil mix without OM. At $800{ }^{\circ} \mathrm{C}$ it decreases by a ratio of 2.2 to $0.6 \mathrm{~W} / \mathrm{mK}$, as it was defined in the framework. The thermal conductivity of OM was assumed to be constant with temperature. Volume fractions of both organic and inorganic parts vary from 0.25 and 0.75 to 0 and 1 , respectively (Table 5), following the normalized thermal decomposition curve (Fig. 9). The resulting temperature dependency of $\lambda_{s}$ of soil mix is presented in Fig. 10.

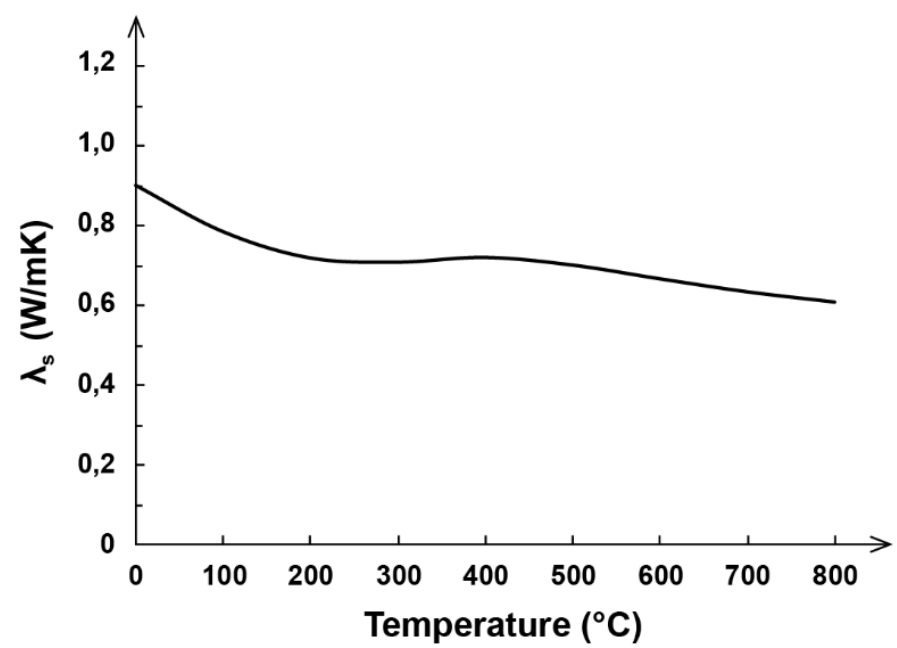

Fig. 10. Variation of thermal conductivity of soil mix solids $\left(\lambda_{s}\right)$ with temperature

Effect of interparticle thermal radiation

The radiation contribution to the effective thermal conductivity was determined 
with Eq. 8, assuming particle emissivity equal to 0.9 . From the data provided by the manufacturer $d_{10}$ is $2 \mathrm{~mm}$. The results presented at Fig. 11 show that the radiative thermal conductivity greatly increases with temperature.

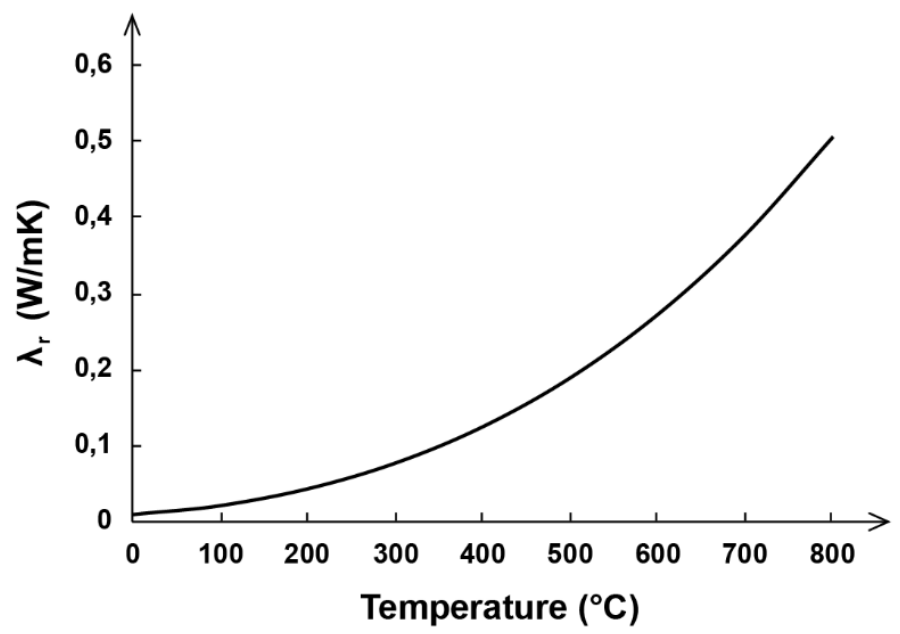

Fig. 11. Radiative thermal conductivity $\left(\lambda_{r}\right)$

\section{Global thermal conductivity relationship}

Prediction of the thermal conductivity of a dry soil mix $\left(\lambda_{c}\right)$ at different temperatures is made with Eq. 1, knowing temperature dependency of solid and fluid phases. With the limited data available it is assumed that porosity remains constant with temperature. Having shown in Fig. 8 that the structure parameter is about the same before and after decomposition of $\mathrm{OM}$, it is assumed that the dependency of $\kappa_{2 \mathrm{P}}$ to temperature is only owed to changes of the $\lambda_{f} / \lambda_{s}$ ratio. This relationship is obtained with Eq. 2 and is shown in Fig. 12.

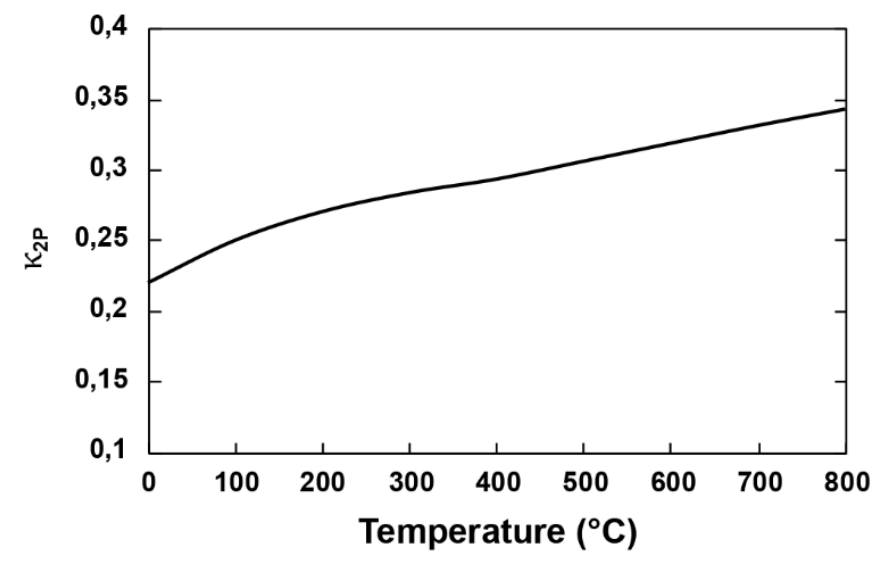

Fig. 12. Structure parameter $\kappa_{2 p}$ change with temperature

Figure 13 presents thermal conductivity of the growing medium with a porosity of 0.6 predicted for a range of temperatures from 0 to $800{ }^{\circ} \mathrm{C}$. And finally, the effective thermal conductivity, that includes the radiation effect, is displayed in Fig. 14. It is seen that contribution from radiation to thermal conduction at elevated temperatures is noticeable. 


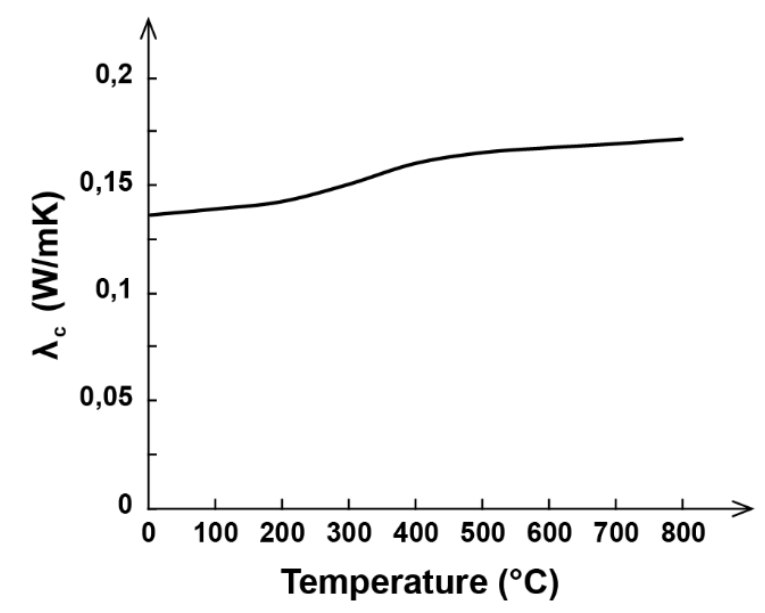

Fig. 13. Temperature dependence of thermal conductivity $\left(\lambda_{c}\right)$ of soil mix



Fig. 14. Temperature dependence of effective thermal conductivity $\left(\lambda_{e}\right)$ of soil mix

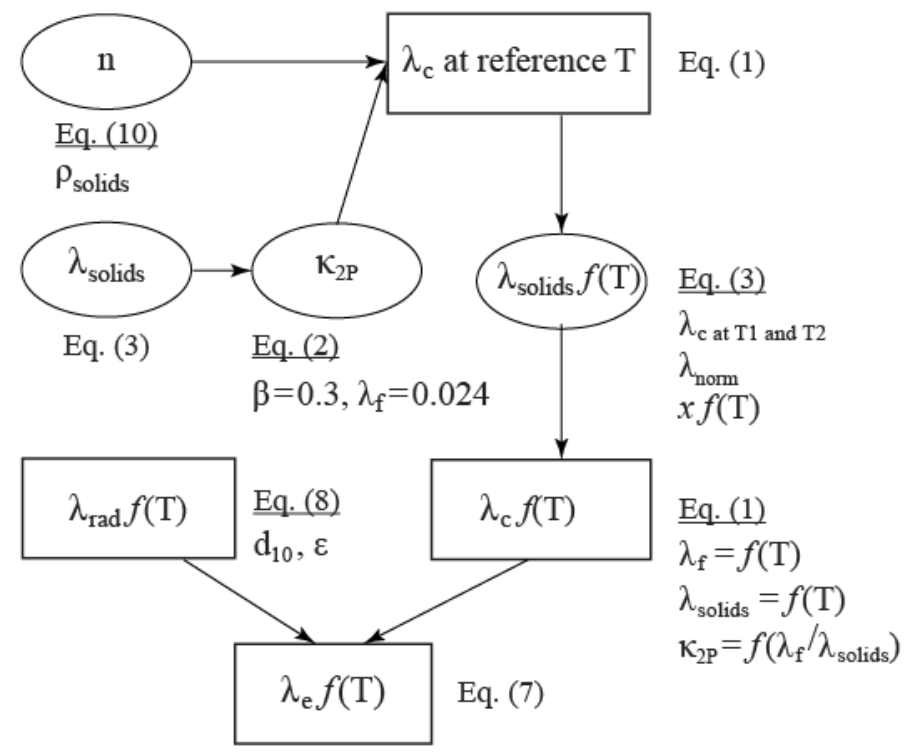

Fig. 15. Scheme for predicting the thermal conductivity 


\section{Thermal conductivity model application over a range of temperatures}

The scheme on Fig. 15 shows the application of the model for calculating green roof dry substrate thermal conductivity and prediction for the elevated temperatures.

\section{Validation}

\section{Testing Procedure}

For the validation of the results of calculated thermal conductivity, the heat transfer test and the numerical solution were performed. Despite the absence of standard verification tests for the thermal conductivity at high temperatures, several authors have previously performed experiments on recording the evolution of temperatures in soil during extreme heating (Aston and Gill 1976; Campbell et al. 1995; Antilén et al. 2006; Enninful 2006). They elaborated mathematical models of heat conduction to simulate the test conditions.

In this research, the test conditions were inspired by the work of Enninful (2006) for the ease of applying heating load on a soil surface, using a cone calorimeter. This apparatus was designed to test material flammability characteristics (Babrauskas 2016). A small sample with a surface of $100 \times 100 \mathrm{~mm}$ is exposed to a certain radiant heat, which is emitted by an electric resistance cone-shape heater. The distance between the base of the heater and the top of a sample was $25 \mathrm{~mm}$. The heat emitter is calibrated according to ISO 5660-1 (2015) to establish a uniform incident heat flux over the sample surface.

A special sample holder was constructed to hold the growing medium. The holder consisted of 4 walls and a bottom, made of rigid non-combustible high temperature insulation material of $12.5 \mathrm{~mm}$ thickness, constructed so that the internal dimensions of soil samples were $100 \times 100 \times 80 \mathrm{~mm}$. The wall material was chosen with a low thermal conductivity of $0.1 \mathrm{~W} / \mathrm{mK}$ to reduce heat loss from the sides. Walls were bonded by a metal frame along the joints. Dried soil sample was placed inside and compacted to a desired density, placing 3 thermocouples at depths of $20 \mathrm{~mm}, 40 \mathrm{~mm}$, and $60 \mathrm{~mm}$ along the center line of the sample (Fig. 16). Experiments were conducted for two porosities of the growing medium, 0.66 and 0.61 , and repeated twice. The continuous radiant heat flux of $50 \mathrm{~kW} / \mathrm{m}^{2}$ was applied vertically over the top of the sample by the cone calorimeter (Fire Testing Technology Ltd, East Grinstead, UK) for $1 \mathrm{~h}$. Temperature readings were taken every 10 seconds.

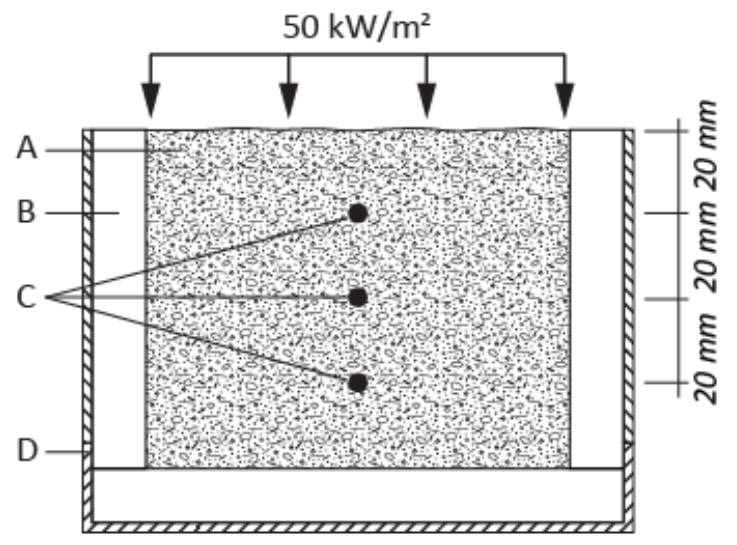

Fig. 16. Sample: A - substrate, B - rigid insulation, C - thermocouples, D - metal frame 


\section{Modelling}

In order to simulate the heat transfer test, a simplified one-dimensional transient heat conduction model was created using ANSYS Mechanical (version 18.2) finite element method based software. The analysis was performed solving Eq. 13,

$$
\rho C_{p} \frac{\partial T}{\partial t}=\frac{\partial}{\partial z}\left(\lambda_{e}(T) \frac{\partial T}{\partial z}\right)
$$

where $\lambda_{e}$ is the temperature dependent effective thermal conductivity (W/mK), $C_{P}$ is soil specific heat $(\mathrm{J} / \mathrm{kgK}), \rho$ is the density of a sample $\left(\mathrm{g} / \mathrm{cm}^{3}\right), z$ is a soil depth $(\mathrm{mm})$, and $T$ is the sample temperature $(\mathrm{K})$.

For initial (Eq. 14) and boundary conditions (Eq. 15 and 16), the following equations were used:

$$
\begin{aligned}
& T(z, t=0)=T_{0}=22^{\circ} \mathrm{C} \\
& z=L, t \geq 0, \quad T=T_{0}
\end{aligned}
$$

It is assumed that the heat from the radiant emitter is transferred to the specimen surface by radiation only, due to a closeness of both emitting and receiving surfaces. Convection heat losses from the sample surface are neglected, as the air above the surface is not expected to be low. Thus, the boundary condition for the specimen surface is expressed as,

$$
z=0, \quad-\lambda_{e}(T) \frac{\partial T}{\partial z}=q_{n e t, r}^{\prime \prime}=\varepsilon \sigma\left(T_{S}^{4}-T_{r}^{4}\right)
$$

where $q^{\prime \prime}{ }_{n e t, r}$ is net radiative heat flux equal to $50 \mathrm{~kW} / \mathrm{m}^{2} ; T_{S}$ is source temperature, 751.5 ${ }^{\circ} \mathrm{C} ; T_{r}$ is temperature of a receiving surface of a soil; $\varepsilon$ is emissivity, assumed equal to 0.8 ; and $\sigma$ is the Stefan-Boltzmann constant, $5.67 \times 10^{-8} \mathrm{~W} / \mathrm{m}^{2} \mathrm{~K}^{4}$.

In this preliminary validation phase, heat generation caused by the thermal decomposition of $\mathrm{OM}$ is not included in a current model due to a complexity of a process itself. Occurring between 150 and $650{ }^{\circ} \mathrm{C}$, the thermal decomposition passes through several stages, as can be seen from the test in Fig. 6. Also, composting material itself has a complex shape and composition (composting sawdust with manure and small inclusions of peat moss), which can result in heat releasing at different rates during burning. Finally, in cases of well compacted substrate, the access of the necessary amount of oxygen to the deeper layers may be restricted, causing insufficient burning and thus less energy production (DeBano et al. 1998). Therefore, it is difficult to simulate such process in detail. Separate research should be conducted for better understanding of mechanisms and obtaining necessary parameters for a model.

In the model, substrate of $80 \mathrm{~mm}$ depth was divided into 32 uniform linear elements and a time step of $10 \mathrm{~s}$ was applied.

\section{Substrate properties}

Modelling was performed using two different temperature-dependent $\lambda_{e}$ that were calculated for porosities of 0.66 and 0.61 . Both tested porosities were assumed to be constant with temperature. The density was obtained from the normalized thermal decomposition of OM, considering that the density of solid particles increases (Table 2). Specific heat of a substrate was calculated as a sum of specific heats of its components multiplied by their mass fractions in a mix (Eq. 17) (De Vries and Van Wijk 1963),

$$
C_{P}=\sum_{i=1}^{n} C_{P_{i}} x_{i}
$$


where $C_{P i}$ is the specific heat of each component $(i)$ in $\mathrm{J} / \mathrm{kgK}$ and $x_{i}$ is their mass fractions. Neglecting the air component, mineral and organic parts are considered. The specific heat of OM solids is taken at $1925 \mathrm{~J} / \mathrm{kgK}$ (De Vries 1954). Extensive literature data for minerals and solid rocks shows that for most of them, specific heat varies within relatively narrow limits between 700 and $800 \mathrm{~J} / \mathrm{kgK}$ with the average value of $770 \mathrm{~J} / \mathrm{kgK}$ (Waples and Waples 2004).

Temperature dependent specific heat for the growing medium is obtained considering the effect of temperature on its inorganic part, as well as on mass fractions. Specific heat of OM is assumed to be constant. Waples and Waples (2004) developed the general equation that describes temperature dependence of specific heat of all minerals and non-porous rocks at a range from 0 to $1200{ }^{\circ} \mathrm{C}$. Using their model, it is possible to predict this property at a desired temperature of a certain material on the condition that its value at a certain temperature is known (Eq. 18),

$$
C_{P_{T 2}}=C_{P_{T 1}} \cdot C_{P n_{T 2}} / C_{P n_{T 1}}
$$

where $C_{P_{T 1}}$ is known specific heat capacity $(\mathrm{J} / \mathrm{kgK})$ at a certain temperature $T_{1}\left({ }^{\circ} \mathrm{C}\right), C_{P n_{T 2}}$ is the normalized specific heat capacity at the temperature of interest $\mathrm{T}_{2}, C_{P n_{T l}}$ is the normalized specific heat capacity at a certain temperature $T_{l}$. The introduced normalized specific heat capacity is given as:

$$
C_{P n_{T}}=8.95 \cdot 10^{-10} T^{3}-2.13 \cdot 10^{-6} T^{2}+0.00172 T+0.716
$$

This normalized specific heat represents best-fit curve of normalized specific heat capacities of all studied rocks and minerals. Their normalized values were obtained by dividing the existed values of each material at different temperatures by their values at 200 ${ }^{\circ} \mathrm{C}$.

Mass fractions for different temperatures are taken from the thermal analysis, where $x_{\mathrm{OM}}$ decreases from 0.164 to 0 . As a result, the curve for specific heat of soil is obtained as a function of temperature (Fig. 17).



Fig. 17. Specific heat of soil mix $\left(C_{p}\right)$ changes with temperature

\section{Validation of results}

Results of temperature evolution at three different depths obtained from the experimental work and numerical simulation are shown in Fig. 18 for the growing medium 
of two different porosities. Solid lines present predicted temperatures and the dashed lines are the measured values. It is seen that using effective thermal conductivity calculated as proposed in this study results in smaller values of temperature at all depths and for the whole duration of the simulation. However, all curves follow the similar shapes of the temperature curves from the experiment.

a)

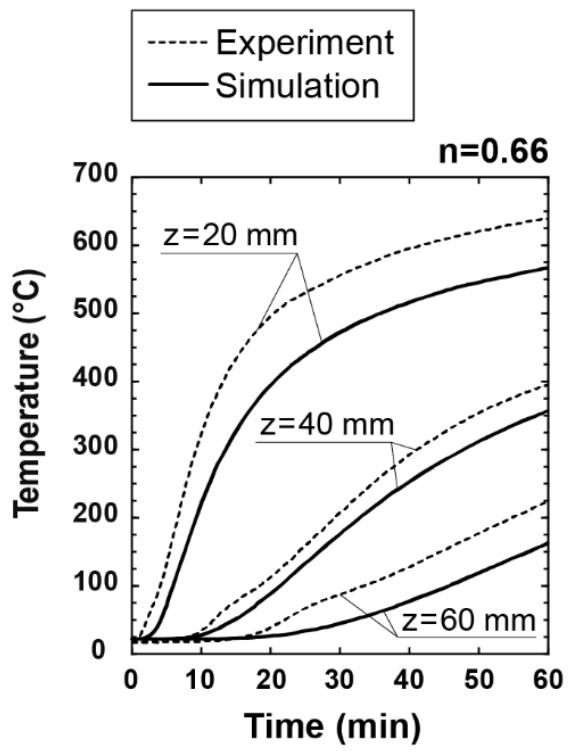

b)

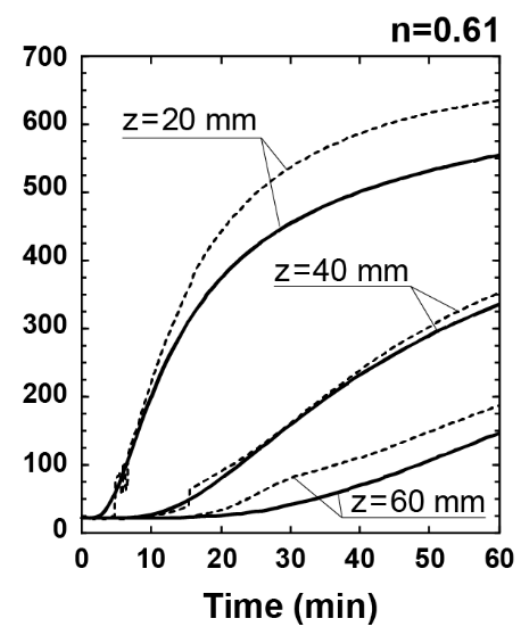

Fig. 18. Results on calculated and measured temperature developments at depths 20,40 and 60 $\mathrm{mm}$ in soils samples: a) with a porosity $0.66, \mathrm{~b}$ ) with a porosity 0.61

The main source of discrepancy between results can be the heat generated by the decomposition of OM, which was not considered in the model. Also, the height of the sample, which was limited by the apparatus geometry, may not be sufficient to represent a semi-infinite solid.

\section{CONCLUSIONS}

1. The existing model for the determination of thermal conductivity of two-phase porous materials is suitable for dry green roof substrates at ambient temperature. The model requires taking the parameter $\beta$ equal to 0.3 , which was evaluated specifically for green roof substrate in order to obtain structure parameter.

2. Experimental results of a dry substrate show the effects of porosity, causing an increase in the thermal conductivity with decreasing porosity.

3. For the prediction of thermal conductivity at elevated temperatures, the decomposition of organic matter and the effect of heat on thermal properties of solid inorganic part are considered. Together with added interparticle radiation effect, the effective thermal conductivity of a substrate shows a substantial increase with increasing temperature compared to the thermal conductivity at normal temperatures. 
4. Temperature-dependent thermal conductivity of dry growing medium, obtained as described in present study, can be suitable for the prediction of temperature profiles in fire. Inclusion of a heat generation in simulations is suggested, which can improve the accuracy of the models. Also, attention must be paid to the natural processes occurred on green roofs, such as settlement of a substrate with time. Roofs that have reached maturity have more compacted substrate than newly installed.

\section{ACKNOWLEDGMENTS}

The authors are grateful to Natural Sciences and Engineering Research Council of Canada for the financial support through its ICP and CRD programs (IRCPJ 461745-12 and RDCPJ 445200-12) as well as the industrial partners of the NSERC industrial chair on eco-responsible wood construction (CIRCERB).

\section{List of Symbols}

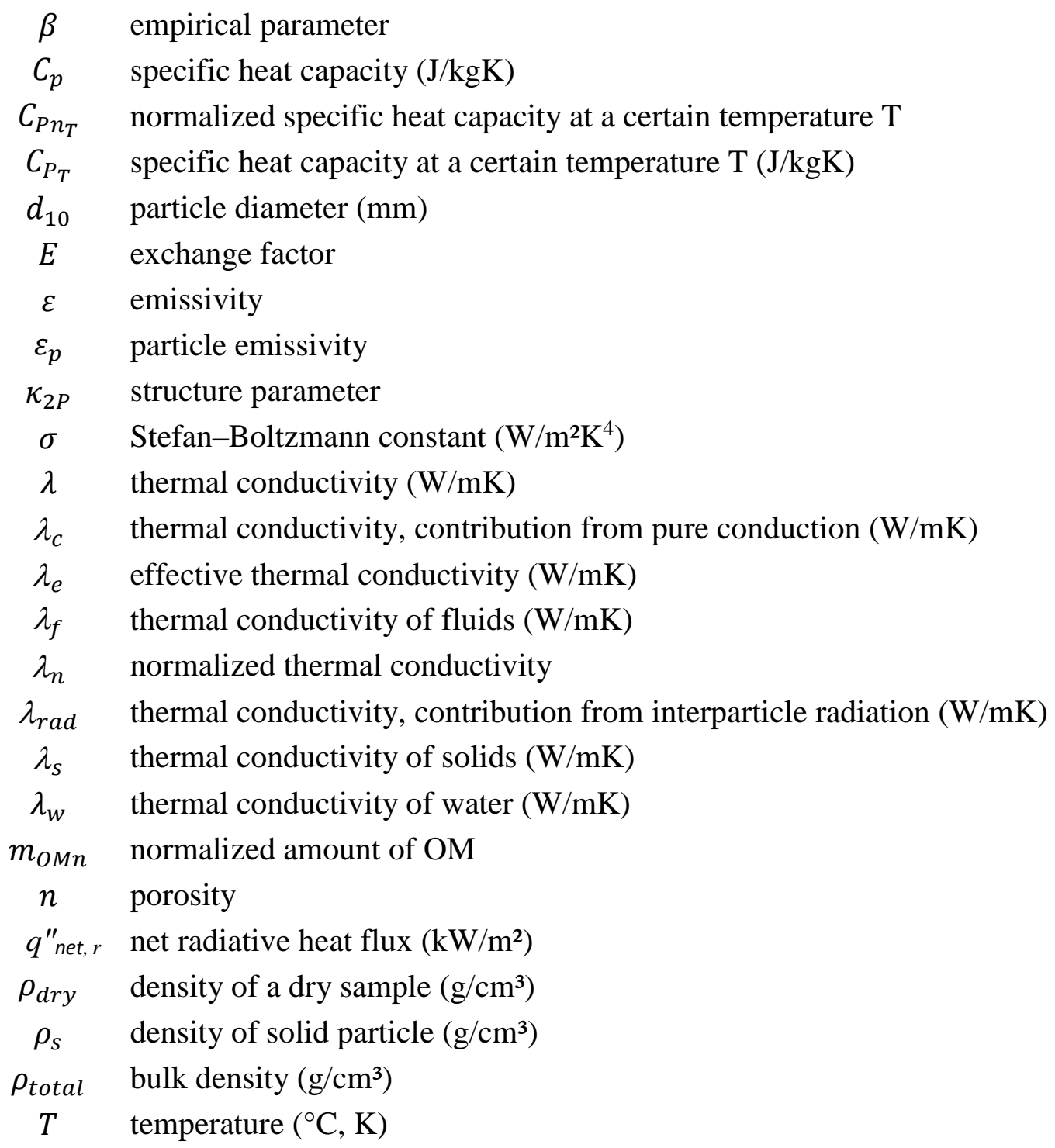


$T_{0} \quad$ initial temperature $\left({ }^{\circ} \mathrm{C}\right)$

$x_{i} \quad$ volume fraction

\section{REFERENCES CITED}

Antilén, M., Fudym, O., Vidal, A., Foerster, J. E., Moraga, N., and Escudey, M. (2006). "Mathematical modelling of temperature profile of volcanic soils affected by an external thermal impact," Australian Journal of Soil Research 44, 57-61. DOI: 10.1071/SR05038

Argo, W. B., and Smith, J. M. (1953). "Heat transfer in packed beds-prediction of radial rates in gas-solid beds," Chemical Engineering Progress 49(8), 443-451.

ASTM D854-14 (2014). "Standard test methods for specific gravity of soil solids by water pycnometer," ASTM International, West Conshohocken, PA, USA.

ASTM D2974 (2014). "Standard test methods for moisture, ash, and organic matter of peat and other organic soils," ASTM International, West Conshohocken, PA, USA.

ASTM D5334-14 (2014). "Standard test method for determination of thermal conductivity of soil and soft rock by thermal needle probe procedure," ASTM International, West Conshohocken, PA, USA.

Aston, A., and Gill, A. (1976). "Coupled soil moisture, heat and water vapour transfers under simulated fire conditions," Australian Journal of Soil Research 14(1), 55-66. DOI: $10.1071 /$ SR9760055

Babrauskas, V. (2016). "The cone calorimeter," in: SFPE Handbook of Fire Protection Engineering, M. J. Hurley (ed.), Springer, New York, NY, pp. 956-960. DOI: 10.1007/978-1-4939-2565-0_28

Becker, D., and Wang, D. (2011). Green Roof Heat Transfer and Thermal Performance Analysis (Unpublished Report), Civil and Environmental Engineering, Carnegie Mellon University, Pittsburgh, PA, USA.

Bergman, T. L., and Incropera, F. P. (2011). "Appendix A", in: Fundamentals of Heat and Mass Transfer, John Wiley \& Sons, Hoboken, NJ, USA.

Campbell, G., Jungbauer, Jr J., Bidlake, W., and Hungerford, R. (1994). "Predicting the effect of temperature on soil thermal conductivity," Soil Science 158(5), 307-313. DOI: 10.1097/00010694-199411000-00001

Campbell, G. S., Jungbauer, Jr J., Bristow, K. L., and Hungerford, R. (1995). "Soil temperature and water content beneath a surface fire," Soil Science 159(6), 363-374. DOI: 10.1097/00010694-199506000-00001

Carson, T., Hakimdavar, R., Sjoblom, K., and Culligan, P. J. (2012), "Viability of recycled and waste materials as green roof substrates," GeoCongress 2012, State of the Art and Practice in Geotechnical Engineering, 3644-3653, 25-29 March, Oakland, CA, USA. DOI: 10.1061/9780784412121.373

Čermák, V., and Rybach, L. (1982). "Thermal conductivity and specific heat of minerals and rocks," in: Numerical Data and Functional Relationships in Science and Technology, New Series, Group V (Geophysics and Space Research), Volume Ia,(Physical Properties of Rocks), G. Angenheister (ed.), Springer, Berlin-Heidelberg, 305-343. DOI: 10.1016/B978-0-08-102051-7.00032-4

Chen, P-Y., Li, Y-H., Lo, W-H., and Tung, C. (2015). "Toward the practicability of a heat transfer model for green roofs," Ecological Engineering 74, 266-273. DOI: 
10.1016/j.ecoleng.2014.09.114

Clark, S. P. (1966). Handbook of Physical Constants, The Geological Society of America, Inc., New York, NY, USA.

Clarke, R. E., Pianella, A., Shabani, B., and Rosengarten, G. (2016). "Steady-state thermal measurement of moist granular earthen materials," Journal of Building Physics 41(2), 101-119. DOI: 10.1177/1744259116637864

Clauser, C., and Huenges, E. (1995). "Thermal conductivity of rocks and minerals," in: Rock Physics \& Phase Relations: A Handbook of Physical Constants, American Geophysical Union, Hannover, Germany, pp. 105-126,

Coma, J., Pérez, G., Solé, C., Castell, A., and Cabeza, L. F. (2016). “Thermal assessment of extensive green roofs as passive tool for energy savings in buildings," Renewable Energy 85, 1106-1115. DOI: 10.1016/j.renene.2015.07.074

Côté, J., and Konrad, J-M. (2005). "Thermal conductivity of base-course materials," Canadian Geotechnical Journal 42(1), 61-78. DOI: 10.1139/t04-081

Côté, J., and Konrad, J-M. (2009). "Assessment of structure effects on the thermal conductivity of two-phase porous geomaterials," International Journal of Heat and Mass Transfer, 52(3-4), 796-804. DOI: 10.1016/j.ijheatmasstransfer.2008.07.037

De Vries, D., and de Wit, C. T. (1954). "Die Thermischen eigenschaften der Moorboden und die beeinflussing der nachtfrostgefahr durch eine Sanddecke," Meteorologische Rundschau 7, 5-28.

De Vries, D., and Van Wijk, W. (1963). "Physics of plant environment," in: Environmental Control of Plant Growth, L. T. Evans (ed.), Academic Press, New York, NY, USA.

DeBano, L. F., Neary, D. G., and Ffolliott, P. F. (1998). "Combustion process and heat transfer," in: Fire Effects on Ecosystems, John Wiley \& Sons, New York, NY. ISBN 0-471-16356-2

Dunnett, N., and Kingsbury, N. (2008). Planting Green Roofs and Living Walls, Timber Press, Portland, OR, USA.

Enninful, E. K. (2006). Predicting Temperature Profiles during Simulated Forest Fires, Ph.D. Dissertation, University of Saskatchewan, Saskatchewan, Canada.

Eppelbaum, L., Kutasov, I., and Pilchin, A. (2014). "Thermal properties of rocks and density of fluids," in: Applied Geothermic, Springer, New York, NY. DOI: 10.1007/978-3-642-34023-9

Fillion, M-H., Côté, J., and Konrad J-M. (2011). "Thermal radiation and conduction properties of materials ranging from sand to rock-fill," Canadian Geotechnical Journal 48(4), 532-542. DOI: 10.1139/t10-093

Hashin, Z., and Shtrikman, S. (1962). "A variational approach to the theory of the effective magnetic permeability of multiphase materials," Journal of Applied Physics 33(10), 3125-3131. DOI: 10.1063/1.1728579

Howell, J. R., and Siegel, R. (2010). "Optically Thin and Thick Limits for Radiative Transfer in Participating Media," in: Thermal Radiation Heat Transfer, CRC Press, Boca Raton, FL, USA, pp. 581-614.

ISO 5660-1 (2015). "Reaction-to-fire tests -- Heat release, smoke production and mass loss rate -- Part 1: Heat release rate (cone calorimeter method) and smoke production rate (dynamic measurement)," International Organization for Standardization, Geneva, Switzerland.

Jaffal, I., Ouldboukhitine, S-E., and Belarbi, R. (2012). "A comprehensive study of the impact of green roofs on building energy performance," Renewable Energy 43, 157- 
164. DOI: $10.1016 /$ j.renene.2011.12.004

Kaviany, M. (1995). "Conduction Heat Transfer" in: Principles of heat transfer in porous media, F. F. Ling (ed.), Springerverlag, New York, NY, USA. DOI: 10.1007/978-14612-4254-3

Molineux, C. J., Fentiman, C. H., and Gange, A. C. (2009). "Characterising alternative recycled waste materials for use as green roof growing media in the UK," Ecological Engineering 35, 1507-1513. DOI: 10.1016/j.ecoleng.2009.06.010

Ouldboukhitine, S-E., Belarbi, R., Jaffal, I., and Trabelsi, A. (2011). "Assessment of green roof thermal behavior: A coupled heat and mass transfer model," Building and Environment 46, 2624-2631. DOI: 10.1016/j.buildenv.2011.06.021

Pompeii II, W. C., and Hawkins, T. W. (2011). "Assessing the impact of green roofs on urban heat island mitigation: A hardware scale modeling approach," The Geographical Bulletin 52, 52-61.

Pourhashemi, S. A., Hao, O. J., and Chawla, R. C. (1999). “An experimental and theoretical study of the nonlinear heat conduction in dry porous media," International Journal of Energy Research 23, 389-401. DOI: 10.1002/(SICI)1099114X(199904)23:5<389::AID-ER486>3.0.CO;2-T

Quezada-García, S., Espinosa-Paredes, G., Escobedo-Izquierdo, M. A., VázquezRodríguez, A., Vázquez-Rodríguez, R., and Ambriz-García, J. J. (2017). "Heterogeneous model for heat transfer in green roof systems," Energy and Buildings 139(15), 205-213. DOI: 10.1016/j.enbuild.2017.01.015

RBQ (2015). "Critères techniques visant la construction de toits végétalisés Quebec," 15 16, Québec, QC, Canada. ISBN (PDF): 978-2-550-72653-1

Robertson, E. C. (1988). Thermal Properties of Rocks (Report 88-441), US Geological Survey, Reston, VA, USA.

Saadatian, O., Sopian, K., Salleh, E., Lim, C. H., Riffat, S., Saadatian, E., Toudeshki, A., and Sulaiman, M. Y. (2013). "A review of energy aspects of green roofs," Renewable and Sustainable Energy Reviews 23, 155-168. DOI: 10.1016/j.rser.2013.02.022

Sailor, D. J., Hutchinson, D., and Bokovoy, L. (2008). "Thermal property measurements for ecoroof soils common in the western US," Energy and Buildings 40, 1246-1251. DOI: 10.1016/j.enbuild.2007.11.004

Sailor, D. J., and Hagos, M. (2011). "An updated and expanded set of thermal property data for green roof growing media," Energy and Buildings 43, 2298-2303. DOI: 10.1016/j.enbuild.2011.05.014

Sandoval, V., Bonilla, C. A., Gironás, J., Vera, S., Victorero, F., Bustamante, W., Rojas, V., Leiva, E., Pasten, P., and Suarez, F. (2017). "Porous media characterization to simulate water and heat transport through green roof substrates," Vadose Zone Journal 16(4). DOI: 10.2136/vzj2016.10.0101

Tabares-Velasco, P. C., and Srebric, J. (2012). "A heat transfer model for assessment of plant based roofing systems in summer conditions," Building and Environment 49, 310-323. DOI: 10.1016/j.buildenv.2011.07.019

Tien, C-L., and Drolen, B. (1987). "Thermal radiation in part1culate media with dependent and independent scattering," Annual Review of Heat Transfer 1, 1. DOI: 10.1615/AnnualRevHeatTransfer.v1.30

Todor, D. N. (1976). "Classification of thermal analysis methods," in: Thermal Analysis of Minerals, D. J. Morgan (ed.), Abacus Press, London, UK, pp. 9-33. DOI:

10.1180/claymin.1978.013.1.11

Van Genuchten, M. T. (1980). "A closed-form equation for predicting the hydraulic 
conductivity of unsaturated soils," Soil Science Society of America Journal 44, 892898. DOI: 10.2136/sssaj1980.03615995004400050002x

Vosteen, H.-D., and Schellschmidt, R. (2003). "Influence of temperature on thermal conductivity, thermal capacity and thermal diffusivity for different types of rock," Physics and Chemistry of the Earth $A, B, C$ 28, 499-509. DOI: 10.1016/S14747065(03)00069-X

Waples, D. W., and Waples, J. S. (2004). "A review and evaluation of specific heat capacities of rocks, minerals, and subsurface fluids. Part 1: Minerals and nonporous rocks," Natural Resources Research 13, 97-122. DOI: 10.1023/B:NARR.0000032647.41046.e7

Yang, J., Quian, Y., and Peng, G. (2008). "Quantifying air pollution removal by green roofs in Chicago," Atmospheric Environment 42(31), 7266-7273. DOI: 10.1016/j.atmosenv.2008.07.003

Zoth, G., and Haenel, R. (1988). "Appendix," in: Handbook of Terrestrial Heat-Flow Density Determination: With Guidelines and Recommendations of the International Heat-Flow Commission, R. Haenel, L. Rybach, and L. Stegena (eds), Springer, Dordrecht, Netherlands, pp. 449-468. DOI: 10.1007/978-94-009-2847-3_10

Article submitted: April 15, 2019; Peer review completed: August 25, 2019; Revised version received and accepted: September 6, 2019; Published: September 12, 2019.

DOI: 10.15376/biores.14.4.8573-8599 